\title{
Minimal NOx emission by Lysinibacillus sphaericus in nutrient poor soil
}

\author{
Melissa Sánchez ${ }^{1}$ and Jenny Dussán ${ }^{1 *}$ \\ ${ }^{1}$ Centro de Investigaciones Microbiológicas - CIMIC, Departamento de Ciencias Biológicas, \\ Universidad de los Andes, Bogotá, Colombia
}

\begin{abstract}
The aim of this study was to determine whether nitrogen dioxide emissions by Lysinibacillus sphaericus exist in nutrient poor soil. First, we evaluated the presence of two genes involved in denitrification (nosF and nosD) by PCR screening of five strains of L. sphaericus (III (3)7, OT4b.49, OT4b.25, OT4b.31 and CBAM5). We then applied a bacterial consortium made up by L. sphaericus III (3)7 and OT4b.49 into closed microcosms of soil and with minimum salts medium (MSM) supplemented with ammonia to measure the concentration of produced nitrogen dioxide over time. The assays with closed microcosms showed a minimum level of nitrogen dioxide over time. The nos $F$ and nosD primers amplified the expected fragment for the five strains and the sequenced nosF and nosD PCR product showed an ATPase domain and a copper-binding domain respectively, which was consistent with the function of these genes. The basal emission of nitrogen dioxide by L. sphaericus in soil is coupled to its ability to enhance the nitrogen bioavailability for soils deficient in nutrients. Therefore, our results indicate that this microorganism can be considered as a good candidate to validate the low emission of NOx in field and in the future as an alternative for biofertilization.
\end{abstract}

Keywords: Lysinibacillus sphaericus, nitric oxide, nitric dioxide, biofertilization, denitrification

\section{Introduction}

Nitrogen constitutes one of the most important nutrients for the sustainability of life on Earth. Unfortunately, the balance of this element transformation has been altered by anthropogenic sources, mainly by combustion and chemical fertilization processes (Fowler et al. 2013). One of the fundamental losses of nitrogen to the atmosphere happens through nitrogen oxides $\left(\mathrm{NO}-\mathrm{NO}_{2}-\mathrm{N}_{2} \mathrm{O}\right)$. These have adverse effects on the environment due to their implication in the formation of smog, acid rain, global warming and ozone layer depletion (World Health Organization., 2006; Portmann et al., 2012).

The main source of these compounds is anthropogenic as they are produced from fossil fuel combustion. However, bacterial nitrification and denitrification also contribute largely to the emission of nitrogen oxides (Tortoso and Hutchinson., 1990; Kool et al., 2011). It is known that bacterial nitrification is carried out only by autotrophic organisms that belong to $\beta$ subclasses of Proteobacteria, such as Nitrospira, Nitrobacter and Nitrosococcus spp (Levy-Booth et al., 2014). On the other hand, denitrification by bacteria is performed by a wide range of organisms such as Pseudomonas spp and Paracoccus denitrificans (an aerobic denitrifier), which is the most representative bacteria of the Proteobacteria group (Hayatsu et al., 2008).

However, it has been found that heterotrophic bacilli are also involved in nitrification and denitrification (Verbaendert et al., 2011). (Kim et al., 2005) characterized the presence of Bacillus strains (Bacillus cereus, Bacillus subtilis and Bacillus licheniformis) in these processes for wastewater treatment. Also, there is genomic evidence for genes related to the nitrogen cycle for gram-positive bacilli (Lin et al., 2010). Particularly for Lysinibacillus sphaericus, the presence of genes such as nifU for nitrogen fixation (Hu et al., 2008; Peña-Montenegro and Dussán., 2013), nitrate reductase (Peña-Montenegro et al., 2015) and nosD, nosF, and nosL involved in denitrification (Rey et al., 2016b; Gomez-Garzón et al., 2016) suggests that this microorganism could also be involved in these processes.

It was also found that $L$. sphaericus can fix nitrogen gas as ammonium and perform in vitro nitrification (Dussán., 2016) where the strains of L. sphaericus III (3)7 and OT4b.49 were the most efficient in this process. Thus, this study aims to evaluate whether L. sphaericus contributes to nitrogen dioxide production when it is added to a nutrient poor soil from the Eastern Llanos basin, Colombia.

*Email: jdussan@uniandes.edu.co 


\section{Materials and Methods}

\section{Bacterial strains and growth conditions}

The five strains of L. sphaericus used in this study are listed in Table 1. They were obtained from the bacteria collection at the Center of Microbiological Research (CIMIC). Nutrient agar was the growth medium used for the microbial consortium (L. sphaericus III (3)7 and OT4b.49), it was incubated at $30^{\circ} \mathrm{C}$ for 48 hours and used for the closed microcosms assays.

\section{Amplification of nosF and nosD genes}

PCR screening was performed for five strains of $L$. sphaericus (III (3)7, OT4b.49, OT4b.25, OT4b.31 and CBAM5). The set of primers used to amplify a partial codification region of $\operatorname{nos} F$ were: nosFf (Forward primer) 5'-TTGAAGCGTGTTTCCTTGTG-3' and nosFr (Reverse primer) 5'-AATTTCAGTGATCGGACCAGA- 3'. The amplification procedure was: $95^{\circ} \mathrm{C}$ for one minute, then 30 cycles of $95{ }^{\circ} \mathrm{C}$ for $30 \mathrm{~s}, 54{ }^{\circ} \mathrm{C}$ for $30 \mathrm{~s}$ and $72{ }^{\circ} \mathrm{C}$ for $30 \mathrm{~s}$, followed by one cycle of $72{ }^{\circ} \mathrm{C}$ for 5 minutes.

For the partial coding sequence of nos $D$ amplification procedure, the following primers were obtained: nosDf (Forward 92 primer) 5'- TGACACTCAACAGGCAAAGG-3' and nosDr (Reverse primer) 5'-CCATCCATTGACCAAAGCTC- 3'.The PCR procedure involved one step of $95^{\circ} \mathrm{C}$ for one minute, then 30 cycles of $95{ }^{\circ} \mathrm{C}$ for $30 \mathrm{~s}, 49^{\circ} \mathrm{C}$ for $30 \mathrm{~s}$, and $72{ }^{\circ} \mathrm{C}$ for $30 \mathrm{~s}$, followed by a final step of $72{ }^{\circ} \mathrm{C}$ for 5 minutes. The primers used for the amplification of both genes were designed using the sequences annotated from the genomes

Table 1: Bacterial strains used in this study

\begin{tabular}{lll}
\hline Strain & Isolation source & Reference \\
\hline L. sphaericus CBAM5 & Subsurface soil of oil well explorations & (Peña-Montenegro et al., 2015) \\
L. sphaericus OT4b.25 & Beetle larvae & (Rey et al., 2016) \\
L. sphaericus OT4b.31 & Beetle larvae & (Peña-Montenegro \& Dussán, 2013) \\
L. sphaericus III (3)7 & Soil & (Rey et al., 2016) \\
L. sphaericus OT4b.49 & Beetle larvae & (Gómez-Garzón et al., 2016) \\
\hline
\end{tabular}

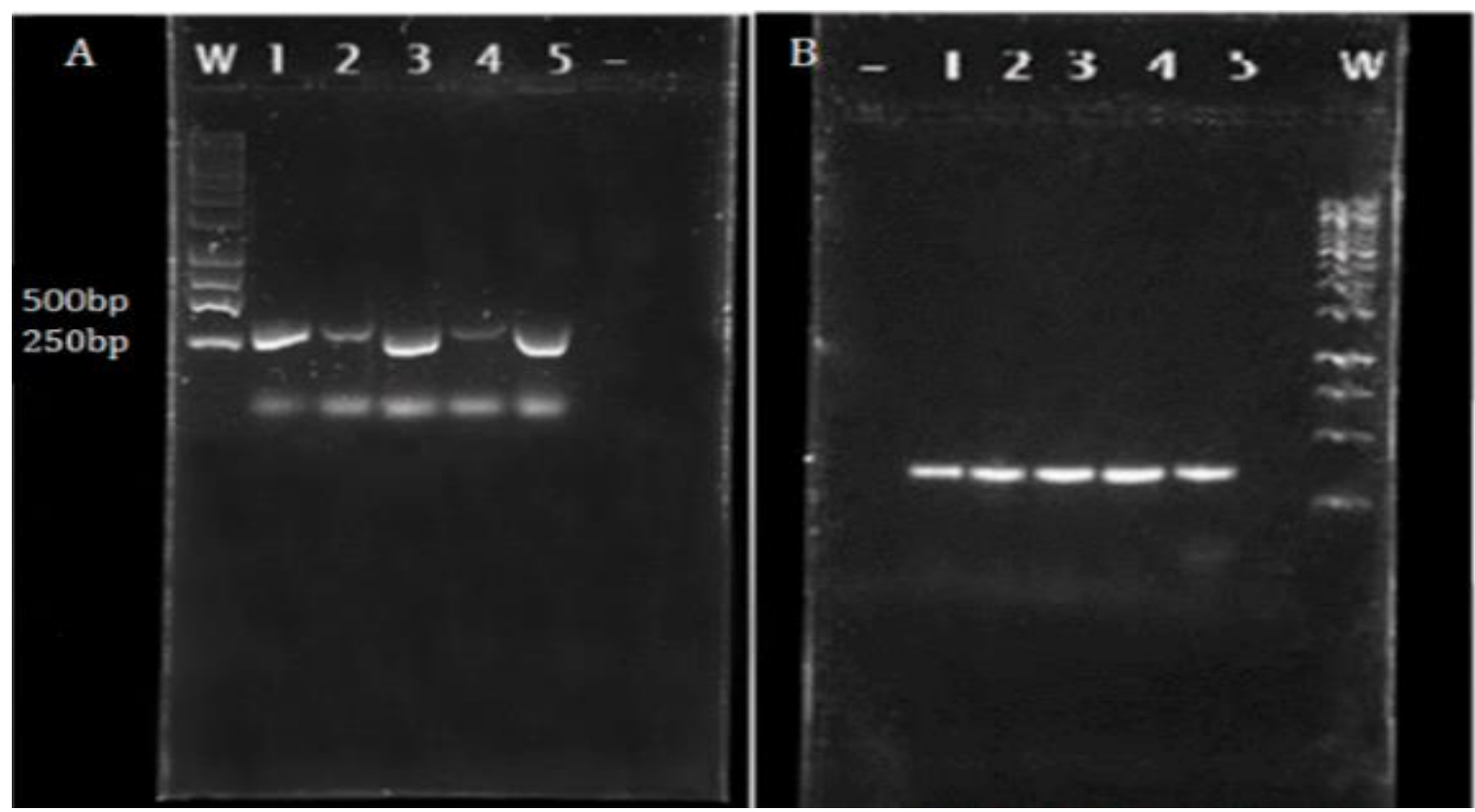

500 bp $250 \mathrm{bp}$

Figure 1: $1.5 \%$ agarose gels with the PCR products of nos $D$ and nosF amplification for $L$. sphaericus strains A). The expected band size for nos $D$ is of 320 bp. Lane order is as follows: W (Weight marker Gene Ruler $1 \mathrm{~kb}$ DNA ladder (Invitrogen), 1 (strain CBAM5), 2 (strain OT4b.25-positive control), 3 (strain OT4b.31), 4 (strain III (3)7), 5 (strain OT4b.49) and - (negative control). B) The expected band size for nosF is of 309 bp. Lane order is as follows: - (negative control), 1(strain CBAM5), 2 (strain OT4b.25-positive control), 3 (strain OT4b.31), 4 (strain III (3)7), 5(strain OT4b.49) and W Weight marker Gene Ruler 1kb DNA ladder (Invitrogen). 
of L. sphaericus OT4b.25, III (3)7 and OT4b.49 (Rey et al., 2016a; Gómez-Garzón et al., 2016). For both PCR procedures this strain was used as positive control. The amplification products were visualized in $1.5 \%$ agarose gel at $90 \mathrm{~V}$ for 70 minutes, purified and sequenced by the DNA Sequencing Laboratory (Universidad de los Andes).

\section{Sequence analysis}

Primary sequences were cleaned with CLC Main Workbench and then the nucleotides obtained and their corresponding deduced amino acid sequences were compared against GenBank database using BLASTN from the National Center for Biotechnology Information. We also carried out a conserved domains analysis with the amino acids sequences using Pfam and Interpro (EMBL-EBI).

\section{Closed microcosms assays}

The substrates used for these assays were nutrient poor soil (low N and P) from Casanare, Colombia and minimal salts medium (Hartsman et al., 1992) supplemented with $0.5 \mathrm{~g} \mathrm{~L}^{-1}$ of ammonia.

Nitrogen oxides emission measurements were performed using the Williams and Fehsenfeld (1991) chamber method with the following modifications: three treatments of $30 \mathrm{~g}$ of mixed soil ( 1 part remediated: 3 parts of clean soil) with another 3 treatments of $30 \mathrm{~mL}$ of minimum salts medium supplemented with ammonia were set up in closed recipients. Following this, a bacterial mix (with $10^{9} \mathrm{UFC} / \mathrm{g}$ as a final concentration for both strains) or bacterial mix with $0.22 \mathrm{~g}$ of fertilizer (NPK) was inoculated into both media. Each treatment was maintained at $30^{\circ} \mathrm{C}$ and it was subjected to 2 replicas. Samples of $10 \mathrm{~mL}$ of air were taken with a syringe on day $0,7,14$, and 21 . These samples were added into closed recipients with an aqueous solution of sodium hydroxide $(\mathrm{pH}$ 9) and then used to indirectly measure the nitric oxide and nitrogen dioxide quantity using SpectroquantNova60A®.

This indirect measurement relies on the aerobic conversion of nitrogen oxide into nitrogen dioxide and oxidation of nitrogen dioxide into nitrite and nitrate according to the following reaction (Kuropka., 2011): $2 \mathrm{NO}_{2}+2 \mathrm{NaOH} \rightarrow \mathrm{NaNO}_{2}+\mathrm{NaNO}_{3}+\mathrm{H}_{2} \mathrm{O}$

Statistical analysis using $\mathrm{R}$ project for Statistical Computing was performed using the Kruskal Wallis test (p-value of $0.05)$.

The amplification results for both denitrification genes showed a band of approximately $300 \mathrm{bp}$ that is consistent with the expected PCR product for all the five strains studied (Figure 1). For $\operatorname{nos} F$ and nosD, the sequences obtained showed $99 \%$ identity with the reference genome for $L$. sphaericus C3-41 (Table 2). The conserved domain analysis for NosF resulted in an ATPase domain, which is consistent with the function that it performs in a NosZ assembly. Furthermore, for NosD, a comparative analysis showed a copper-binding domain for all five sequences according to the domains present for the protein encoded by this gene. Few findings for gene characterization involved in denitrification for Gram-positive bacteria are currently available. (Liu et al., 2008) described functional characteristics of Geobacillus thermodenitrificans NG80-2 nosZ cluster revealing that Gram positive and Gram-negative bacteria have conserved the molecular mechanism related to the final step of denitrification. However, further studies on the nos $Z$ sequence for L. sphaericus along with PCR screening and confirmation of gene expression for all the denitrification genes are required. The presence of atypical nos $Z$ cluster does not necessarily indicate denitrification activity as most of bacteria and archaea do not have other denitrification genes (Sanford et al., 2012). It is also necessary to evaluate the activity of these enzymes and their importance related to nitrogen oxides production, as Beaumont et al., (2002) found that the disruption of nitrite reductase in Nitrosomonas europaea is not sufficient to stop nitric and nitrous oxide production.

Figure 2 shows that there are significant differences between treatments for day 14 , with bigger concentrations for treatments inoculated with the bacterial mix (soil with NPK and MMS) which coincides with the possible biogenic emissions of nitric oxide converted rapidly to nitrogen dioxide by these bacteria (Davidson et al., 2000). As MMS is supplemented with ammonia as nitrogen source, the results obtained indicate that $L$. sphaericus could perform nitrification and denitrification. Both processes generate nitrogen oxides as intermediates (Hayatsu et al., 2008). The measures of nitrite were not included as the results were similar to the detection level. Although the expected ratio of nitrites and nitrates was equal to the unity (Aoki et al., 1982; Kuropka 2011), the excess nitrogen dioxide led to the oxidation of nitric oxide, and the temperature conditions and volume of the microcosm contributed to the greater concentration of nitrate over nitrite. This is consistent with nitrite formation not being the rate-limiting factor from the oxidation of nitrogen dioxide (Aoki et al., 1982). There are few available studies about nitric oxides emissions in soils and they have found that the ratio between nitric and nitrous oxide production varies from 3 to 10:1 (Smith et al., 1997). Thus, in further studies, we would expect lower emissions of nitrous oxide in this particular soil.

In conclusion, the presence of denitrification genes (nosD and nosF) for five strains of $L$. sphaericus could be associated with the activity of this microorganism in vitro as our results showed throughout the study. Although the low NOx emissions obtained need to be validated with field 
Table 2: Sequences obtained in this study for five strains of $L$. sphaericus

\begin{tabular}{llllll}
\hline Sequence name & $\begin{array}{l}\text { GenBank } \\
\text { Accession number }\end{array}$ & $\begin{array}{l}\text { BLASTN } \\
\text { identity }(\boldsymbol{\%})\end{array}$ & $\begin{array}{l}\text { BLASTN } \\
\text { e-value }\end{array}$ & $\begin{array}{l}\text { BLASTX } \\
(\%)\end{array}$ & $\begin{array}{c}\text { identity } \\
\text { BLASTX } \\
\text { e-value }\end{array}$ \\
\hline Nos D partial CDSa & KX981441 & 100 & $8 \mathrm{e}-165$ & 100 & $2 \mathrm{e}-69$ \\
Nos D partial CDSb & KX981442 & 99 & $6 \mathrm{e}-161$ & 98 & $6 \mathrm{e}-67$ \\
Nos D partial CDSc & KX981443 & 99 & $1 \mathrm{e}-163$ & 100 & $2 \mathrm{e}-69$ \\
Nos D partial CDSd & KX981444 & 99 & $1 \mathrm{e}-163$ & 100 & $2 \mathrm{e}-69$ \\
Nos D partial CDSe & KX981445 & 99 & $1 \mathrm{e}-163$ & 100 & $2 \mathrm{e}-69$ \\
Nos F partial CDSa & KX981446 & 100 & $2 \mathrm{e}-130$ & 100 & $9 \mathrm{e}-39$ \\
Nos F partial CDSb & KX981447 & 100 & $4 \mathrm{e}-158$ & 100 & $7 \mathrm{e}-53$ \\
Nos F partial CDSc & KX981448 & 100 & $8 \mathrm{e}-129$ & 10 & $5 \mathrm{e}-38$ \\
Nos F partial CDSd & KX981449 & 100 & $4 \mathrm{e}-158$ & 100 & $7 \mathrm{e}-53$ \\
Nos F partial CDSe & KX981450 & 100 & $1 \mathrm{e}-127$ & 100 & $5 \mathrm{e}-38$ \\
\hline
\end{tabular}

* a: CBAM5, b; OT4b.25, c: OT4b.31,d: III (3)7 and e:OT4b.49.
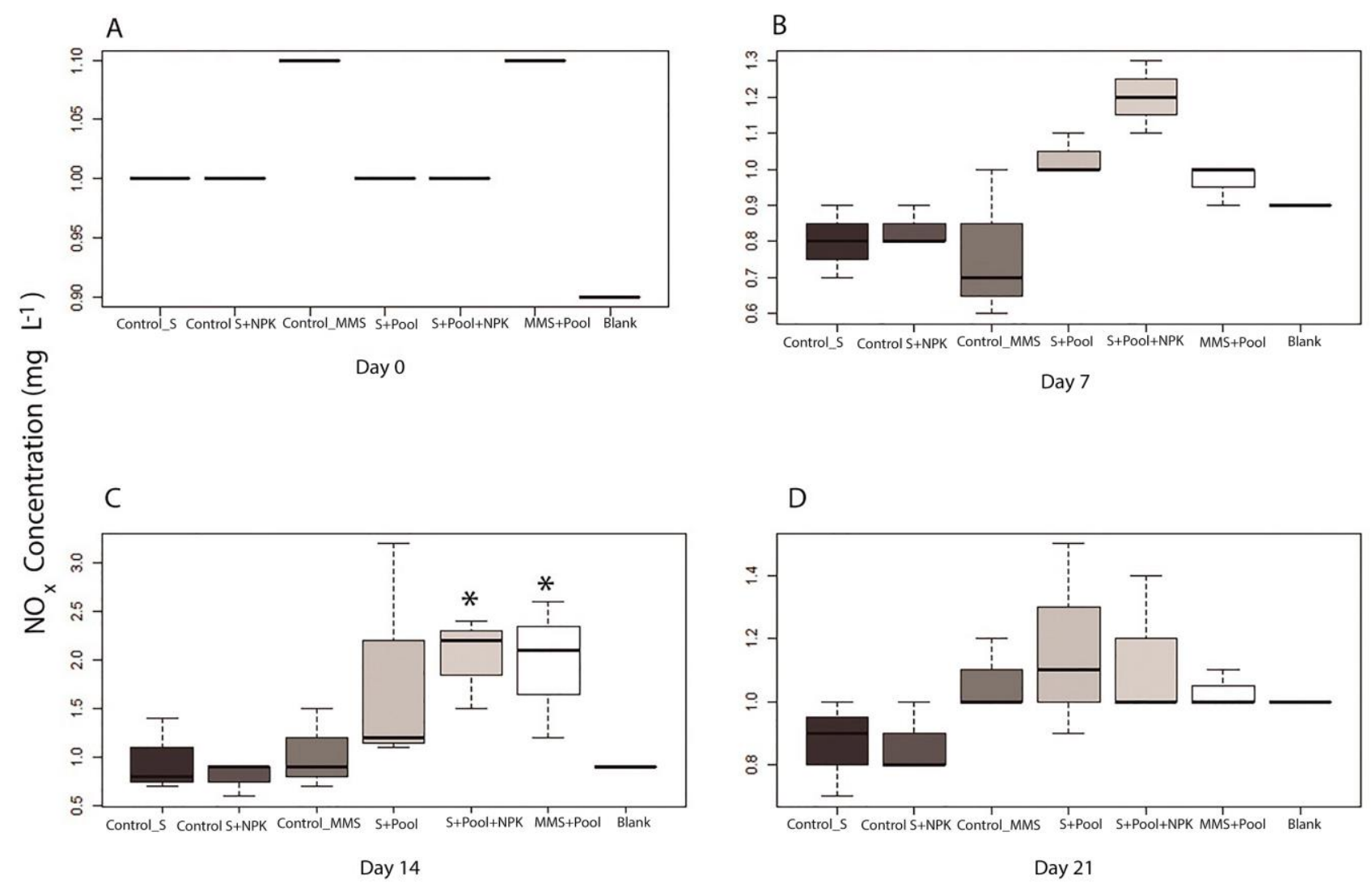

Figure 2: Variation of nitrate concentration for days $0,7,14$ and 21 in close microcosms T0, T7, T14 and T21 refer to the days of sampling, pool refers to the bacterial mix (L. sphaericus III (3)7 and OT4b.49) and NPK is the fertilizer used for this assay. $S$ refers to the soil and MMS to the minimal salts medium supplemented with ammonia. Statistical significance between treatments is indicated by *p value minor to 0.05 (Kruskal-Wallis test)

trials, they provide important evidence related to the ability of L. sphaericus to perform nitrification and denitrification processes. Thus, this microorganism could be considered as a promising candidate for biofertilization. 


\section{Acknowledgements}

This work was performed with grant funds provided by Biointech E. U and the Microbiological Research CenterCIMIC at Universidad de los Andes, Colombia. We would like to thank them for their financial support. We would also like to acknowledge Vladimir Ramirez for the provision of the soil samples used in this study.

\section{References}

Aoki, M., H. Tanaka, H. Komiyama and H. Inoue. 1982. Simultaneous absorption of $\mathrm{NO}$ and $\mathrm{NO}_{2}$ into alkaline solutions. Journal of Chemical Engineering of Japan 15(5):362-367.

Beaumont, H.J., N.G. Hommes, L.A. Sayavedra-Soto, D.J. Arp, D.M. Arciero, A.B. Hooper, H.V. Westerhoff and R.J.M.V. Spanning. 2002. Nitrite reductase of Nitrosomonas europaea is not essential for production of gaseous nitrogen oxides and confers tolerance to nitrite. Journal of Bacteriology 184(9):2557-2560.

Davidson, E., M. Keller, H. Erickson, L. Verchot and E. Veldkamp. 2000. Testing a Conceptual Model of Soil Emissions of Nitrous and Nitric Oxides Using two functions based on soil nitrogen availability and soil water content, the hole-in-the-pipe model characterizes a large fraction of the observed variation of nitric oxide and nitrous oxide emissions from soils. Bioscience 50(8):667-680.

Fowler, D., M. Coyle, U. Skiba, M.A. Sutton, J.N. Cape, S. Reis, L.J. Sheppard, A. Jenkins, J. Grizzetti, J.N. Galloway, P. Vitousek, A. Leah, F. Bouwman, K. Butterbach-Bahl, F. Dentener, D. Stevenson, M. Amann and M. Voss. 2013. The global nitrogen cycle in the twenty-first century. Philosophical Transactions of the Royal Society of London B: Biological Sciences 368(1621):20130164.

Gómez-Garzón, C., A. Hernández-Santana and J. Dussán. 2016. Comparative genomics reveals Lysinibacillus sphaericus group comprises a novel species. BMC Genomics 17(1):709.

Hartsman, S., A. Kaptein, J. Tramper and J.A.M. De Bont. 1992. Characterization of a Mycobacterium sp. and a Xanthobacter sp. for the removal of vinyl chloride and 1, 2-dichloroethane from waste gases. Applied Microbiology and Biotechnology 37(6):796-801.

Hayatsu, M., K. Tago and M. Saito. 2008. Various players in the nitrogen cycle: Diversity and functions of the microorganisms involved in nitrification and denitrification, Soil Science and Plant Nutrition 54(1):33-45.

Hu, X., W. Fan, B. Han, H. Liu, D. Zheng, Q. Li and Z. Yuan. 2008. Complete genome sequence of the mosquitocidal bacterium Bacillus sphaericus C3-41 and comparison with those of closely related Bacillus species. Journal of Bacteriology 190(8):2892-2902.

Kim, J.K., K.J. Park, K.S. Cho, S.W. Nam, T. J. Park and R. Bajpai. 2005. Aerobic nitrification-denitrification by heterotrophic Bacillus strains. Bioresource Technology 96(17): 1897-1906.

Kool, D.M., J. Dolfing, N. Wrage and J.W.V. Groengen. 2011. Nitrifier denitrification as a distinct and significant source of nitrous oxide from soil. Soil Biology and Biochemistry 43(1):174-178.

Kuropka, J. 2011. Removal of nitrogen oxides from flue gases in a packed column. Environment Protection Engineering 37(1): 13-22.

Levy-Booth, D.J., C.E. Prescott and S.J. Grayston. 2014. Microbial functional genes involved in nitrogen fixation, nitrification and denitrification in forest ecosystems. Soil Biology and Biochemistry 75(1):11-25. Lin, Y., H. Kong, D. Wu, C. Li, R. Wang and S. Tanaka. 2010. Physiological and molecular biological characteristics of heterotrophic ammonia oxidation by Bacillus sp. LY. World Journal of Microbiology and Biotechnology 26(9):1605-1612.

Liu, X., C. Gao, A. Zhang, P. Jin, L. Wang and L. Feng. 2008. The nos gene cluster from gram-positive bacterium Geobacillus thermodenitrificans NG80-2 and functional characterization of the recombinant NosZ. FEMS Microbiology Letters 289(1):46-52.

Peña-Montenegro, T.D., L. Lozano and J. Dussán. 2015. Genome sequence and description of the mosquitocidal and heavy metal tolerant strain Lysinibacillus sphaericus CBAM5. Standards in Genomic Sciences 10(1):2.

Peña-Montenegro, T.D. and J. Dussán. 2013. Genome sequence and description of the heavy metal tolerant bacterium Lysinibacillus sphaericus strain OT4b. 31. Standards in Genomic Sciences 9(1):42-56.

Portmann, R.W., J.S. Daniel and A.R. Ravishankara. 2012. Stratospheric ozone depletion due to nitrous oxide: influences of other gases. Philosophical Transactions of the Royal Society of London B: Biological Sciences 367(1593):1256-1264.

Rey, A., L. Silva-Quintero and J. Dussán. 2016a. Complete genome sequence of the larvicidal bacterium Lysinibacillus sphaericus strain OT4b. 25. Genome Announcements 4(3):e00257-16. Rey, A., L. SilvaQuintero and J. Dussán. 2016b. Complete genome sequencing and comparative genomic analysis of functionally diverse Lysinibacillus sphaericus III (3)7. Genomics Data 9:78-86.

Sanford, R.A., D.D. Wagner, Q. Wu, J.C. Chee-Sanford, S.H. Thomas, C. Cruz-García, G. Rodriguez, A. Massol-Deyá, K.K. Krishnani, K.M. Ritalahti, S. Nissen, K.T. Konstantinidis and F.E. Löffler. 2012. 
Unexpected non denitrifier nitrous oxide reductase gene diversity and abundance in soils. Proceedings of the National Academy of Sciences 109(48):19709-19714.

Smith, K.A., I.P. McTaggart and H. Tsuruta. 1997. Emissions of $\mathrm{N}_{2} \mathrm{O}$ and $\mathrm{NO}$ associated with nitrogen fertilization in intensive agriculture, and the potential for mitigation. Soil Use and Management 13(s4):296304. dx.doi.org/10.1111/j.1475-2743.1997.tb00601.x

Tortoso, A.C. and G.L. Hutchinson. 1990. Contributions of autotrophic and heterotrophic nitrifiers to soil $\mathrm{NO}$ and $\mathrm{N}_{2} \mathrm{O}$ emissions. Applied and Environmental Microbiology 56(6):1799-1805.

Verbaendert, I., N. Boon, P.D. Vos and K. Heylen. 2011. Denitrification is a common feature among members of the genus Bacillus. Systematic and Applied Microbiology 34(5):385-391.
World Health Organiztion. 2006. Air Quality Guidelines: Global Update 2005. Particulate Matter, Ozone, Nitrogen Dioxide and Sulfur Dioxide. Resource document. World Health Organization: http://www.euro.who.int/_data/assets/pdf_file/0005/78 638/E90038.pdf?ua=1 [Accessed 25/09/2016].

Williams, E.J. and F.C. Fehsenfeld. 1991. Measurement of soil nitrogen oxide emissions at three North American ecosystems. Journal of Geophysical Research: Atmospheres 96(D1):1033-1042. 